\title{
Risk Factor, Job Stress and Quality of Life in Workers With Lower Extremity Pain Who Use Video Display Terminals
}

\author{
Sehoon Choi, MD, Seong Ho Jang, MD, PhD, Kyu Hoon Lee, MD, PhD , \\ Mi Jung Kim, MD, PhD, Si-Bog Park, MD, PhD, Seung Hoon Han, MD, PhD \\ Department of Rehabilitation Medicine, Hanyang University College of Medicine, Seoul, Korea
}

Objective To investigate the general characteristics of video display terminal (VDT) workers with lower extremity pain, to identify the risk factors of work-related lower extremity pain, and to examine the relationship between work stress and health-related quality of life.

Methods A questionnaire about the general characteristics of the survey group and the musculoskeletal symptom was used. A questionnaire about job stress used the Korean Occupational Stress Scale and medical outcome study 36-item Short Form Health Survey (SF-36) to assess health-related quality of life.

Results There were 1,711 subjects in the lower extremity group and 2,208 subjects in the control group. Age, sex, hobbies, and feeling of loading affected lower extremity pain as determined in a crossover analysis of all variables with and without lower extremity pain. There were no statistically significant difference between the two groups in terms of job stress and SF-36 values of the pain and control groups.

Conclusion Job stress in VDT workers was higher than average, and the quality of life decreased as the stress increased. Factors such as younger age, women, hobbies other than exercise, and feeling of loading influenced lower extremity pain of workers. Further long-term follow-up and supplementary studies are needed to identify risk factors for future lower extremity pain, taking into account ergonomic factors such as worker's posture.

Keywords Work-related lower extremity pain, SF-36, Job stress

\section{INTRODUCTION}

Work-related musculoskeletal disorders (WRMSDs) are defined by the World Health Organization as disorders of muscles, tendons, peripheral nerves, and blood vessels that can be caused, preceded or exacerbated by repeated

Received April 28, 2017; Accepted July 3, 2017

Corresponding author: Seung Hoon Han

Department of Rehabilitation Medicine, Hanyang University Guri Hospital, Hanyang University College of Medicine, 153 Gyeongchun-ro, Guri 11923, Korea. Tel: +82-31-560-2380, Fax: +82-31-564-4654, E-mail: stephan72@hanmail.net

ORCID: Sehoon Choi (http://orcid.org/0000-0003-2840-9783); Seong Ho Jang (http://orcid.org/0000-0001-6267-0980); Kyu Hoon Lee (http://orcid. org/0000-0001-7372-5676); Mi Jung Kim (http://orcid.org/0000-0003-2920-9900); Si-Bog Park (http://orcid.org/0000-0001-8910-2262); Seung Hoon Han (http://orcid.org/0000-0002-9138-4059).

(c) This is an open-access article distributed under the terms of the Creative Commons Attribution Non-Commercial License (http://creativecommons.org/ licenses/by-nc/4.0) which permits unrestricted noncommercial use, distribution, and reproduction in any medium, provided the original work is properly cited. Copyright $\odot 2018$ by Korean Academy of Rehabilitation Medicine 
or continuous use of the body. The US National Institute of Occupational Safety and Health (NIOSH) defines WRMSDs using a concept that includes expressions of all work-related symptoms. According to the NIOSH, workrelated musculoskeletal disorders refer to the cases in which people who did not have an accident or have not been injured in the past experience symptoms of pain, stiffness, burning and numbness in the neck, shoulder, elbow joint, or forearm or upper or lower extremity joints lasting longer than a week or appearing at least once a month for 1 year while working in their current job.

In the past several decades, office automation and informatization have burgeoned and the use of visual display terminal (VDT) has become commonplace. Many working environments feature protracted periods of sitting and extended periods of computer use in a static posture. As a result, a work-related disorder that develops in VDT workers, which has been termed VDT syndrome, has become a wide spread social problem [1]. VDT syndrome refers to a group of diseases occurring in workers whose job features prolonged VDT use. The syndrome encompasses musculoskeletal diseases including lower extremity pain, mental disorders such as mental stress, skin disorders, and pregnancy and reproductive disorders [2-5].

Many domestic and international studies on musculoskeletal diseases in VDT syndrome are being conducted. Most of the studies on musculoskeletal diseases of VDT workers conducted in Korea have focused on the prevalence of symptoms in the neck and upper extremities and their risk factors. Only a few studies have addressed the epidemiology and risk factors for lower extremity pain among work-related musculoskeletal diseases. No study has addressed work-related lower extremity pain, job stress, and health-related quality of life (HRQOL) to our knowledge. Therefore, this study aimed to investigate the general characteristics of office workers with lower extremity pain, to identify the risk factors related to lower extremity pain, and to examine the associations with job stress and HRQOL.

\section{MATERIALS AND METHODS}

\section{Subjects}

This study was conducted on office workers who used a computer for at least 4 hours a day. Two surveys were done. In the first survey of 8,744 people examined the location, duration, frequency, and intensity of the pain. In the second survey, a questionnaire consisting of questions on job stress and HRQOL was used, with 6,672 respondents. Among the respondents who answered the first and second questionnaires, 1,711 persons who had experienced lower extremity pain within the past 1 year were selected for the lower extremity pain group, and 2,208 healthy persons who did not have musculoskeletal symptoms within the past 1 year were selected for the control group.

\section{Method}

The surveys were conducted using a structured questionnaire consisting of three parts. The first part included the subjects' age, gender, the number of working years, drinking, smoking, hobbies, housework hours, feeling of loading, presence of lower extremity pain, and the duration, intensity and frequency of lower extremity pain based on the questionnaire for musculoskeletal disease symptoms used by the Korea Occupational Safety and Health Agency (KOSHA). Among the above items, the number of working years was classified into $<10$ years, 10 to 20 years, and $\geq 21$ years, and drinking and smoking were classified into the presence or absence of the history. Hobby was classified into exercise hobbies, non-exercise hobbies, and none. Housework hour was classified into none, below 1 hour, and 1 hour or more, and feeling of loading was classified into none, tolerable, and nontolerable. The questionnaire on musculoskeletal pain was prepared based on the 'questionnaire for musculoskeletal symptoms' of the KOSHA guideline for the investigation of musculoskeletal burden task hazards. The duration of lower extremity pain was classified into below 1 day, longer than 1 day but below 1 week, and longer than 1 week. The intensity was classified into mild pain, moderate pain, and severe pain, and the frequency was classified into every day, several times per month, and once per several months. The second part was about quality of life, and the short form of Korean Occupational Stress Scale (KOSS) developed by the Institute of Occupational Safety and Health was used. The validity and reliability of KOSS have been verified since its development in 2003. The basic form consists of 43 items and a short form consists of 24 items. In this study, the short form was used. Twentyfour items were measured with a 4-point rating scale 
from 'very disagree' to 'very agree'. Each item had seven subscales including job demand, insufficient job control, interpersonal conflict, job insecurity, organization system, lack of reward, and occupational climate. From the scale, the scores of the seven subscales and the total score obtained by summing all items were generated. The job stress score was expressed as a value obtained by converting these data ranging from 0 (not stressed at all) to 100 (extremely stressed), and the subject's job stress was measured by using the scores of 7 subscales and the total score [2]. In this study, a structured questionnaire with 24 items of 7 subscales was distributed to the patient and control groups, and the data were collected by the self-administered questionnaire survey method, and the answers were scored from the lowest 0 to the highest 100. The third part was about HRQOL, and the medical outcome study 36-item Short Form Health Survey (SF36) was used. SF-36 is a multidimensional generic health profile HRQOL measure consisting of 36 items. It is a generic measure for overall health state rather than for a specific age, disease status, or treatment group. Therefore, SF-36 can be used not only for research targeting the general public, but also for comparison of normal people with patients having a specific disease, comparison of relative disease burdens of various diseases, and comparison of health benefits by various treatment effects. It can also be used as a screening test and is known to be used for evaluation of health policy. Since its first introduction in 1992, SF-36 has been translated and used in many countries due to the simplicity and comprehensiveness of the questionnaire. The validity and reliability of SF36 have been verified through various studies, and it has been proven that SF-36 can be used in large-scale studies [3-6]. In this study, the Korean version SF-36 (KSF-36) was used. The score of SF-36 is expressed as a value ranging from 0 (worst health condition) to 100 (best health condition) obtained by converting the basic data, and it measures HRQOL of the subjects using the scores of eight subscales, two summary index scores, and overall health score. In this study, the scores of KOSS and SF-36 were converted into scores out of 100 .

\section{Statistical analyses}

All data were analyzed using SPSS version 18 for Windows (SPSS Inc., Chicago, IL, USA). To examine the correlations among job stress scores, SF-36 scores, summary measures, and overall health score in the lower extremity pain and control groups, Pearson correlation analysis was performed. The correlation analysis was conducted by adjusting for age, gender, the number of working years, drinking, smoking, hobbies including exercise, housework hours, and feeling of loading. The degree of correlation was evaluated according to the magnitude of the correlation coefficient [7]. Additionally, in order to confirm the associations of lower extremity pain with age,

Table 1. General characteristics of all subjects

\begin{tabular}{|c|c|c|c|}
\hline & $\begin{array}{c}\text { Patient } \\
\text { group }\end{array}$ & $\begin{array}{c}\text { Control } \\
\text { group }\end{array}$ & p-value ${ }^{a)}$ \\
\hline No. of subjects & $1,711(45.0)$ & $2,088(55.0)$ & \\
\hline Age (yr) & $42.8 \pm 5.4$ & $44.7 \pm 5.3$ & $0.000^{*}$ \\
\hline \multicolumn{4}{|l|}{ Gender } \\
\hline Male & $1,140(66.6)$ & $1,754(84.0)$ & \\
\hline Female & $571(33.4)$ & $334(16.0)$ & $0.000^{*}$ \\
\hline \multicolumn{4}{|l|}{ Smoking } \\
\hline Yes & $758(44.3)$ & 756 (36.2) & \\
\hline No & $953(55.7)$ & $1,332(63.8)$ & \\
\hline \multicolumn{4}{|l|}{ Drinking } \\
\hline Yes & $1,497(87.5)$ & $1,827(87.5)$ & \\
\hline No & $214(12.5)$ & $261(12.5)$ & \\
\hline \multicolumn{4}{|c|}{ Working period (yr) } \\
\hline$\leq 10$ & $43(2.5)$ & $22(1.1)$ & $0.000^{*}$ \\
\hline $11-20$ & $1,388(81.1)$ & $1,775(85.0)$ & \\
\hline$\geq 21$ & $280(16.4)$ & 291 (13.9) & \\
\hline \multicolumn{4}{|l|}{ Hobby } \\
\hline Exercise & $1,010(59.0)$ & $1,619(77.5)$ & \\
\hline Non-exercise & 204 (11.9) & $185(8.7)$ & \\
\hline None & $497(29.1)$ & $284(13.8)$ & $0.000^{*}$ \\
\hline \multicolumn{4}{|c|}{ Housework hours (per day) } \\
\hline None & $439(25.7)$ & $746(35.7)$ & \\
\hline$<1$ & $622(36.4)$ & $950(45.5)$ & \\
\hline$\geq 1$ & $650(37.9)$ & $392(18.8)$ & $0.000^{*}$ \\
\hline \multicolumn{4}{|l|}{ Feeling of loading } \\
\hline None & $151(25.7)$ & $480(23.0)$ & \\
\hline Tolerable & $862(50.4)$ & $1,357(65.0)$ & \\
\hline Non-tolerable & $698(23.9)$ & $251(12.0)$ & $0.000^{*}$ \\
\hline
\end{tabular}

$\overline{\text { Values are presented as number (\%) or mean } \pm \text { standard }}$ deviation.

${ }^{a)} \mathrm{p}$-values were calculated using the independent t-test and chi-square test.

${ }^{*} \mathrm{p}<0.05$. 
gender, the number of working years, drinking, smoking, hobbies including exercise, housework hours, and feeling of loading, cross-tabulation was performed using the chi-square test and linear versus linear combination. The job stress scores, SF-36 scores, summary measures, and overall health score of the lower extremity pain group were compared with those of the control group by independent t-tests. The differences in job stress scores, SF36 scores, summary measures, and overall health score according to age, gender, the number of working years, drinking, smoking, hobby including exercise, housework hours, and feeling of loading between the lower extremity pain and control groups were analyzed by independent t-tests and ANOVA. In order to predict the quality of life score from the total job stress score, a regression equation was obtained by linear regression analysis. In order to find an appropriate model to explain the dependent variable and the effects of independent variables (age,

Table 2. Univariate analysis and multiple logic regression models relating cross-sectional potential predictors to lower extremity pain

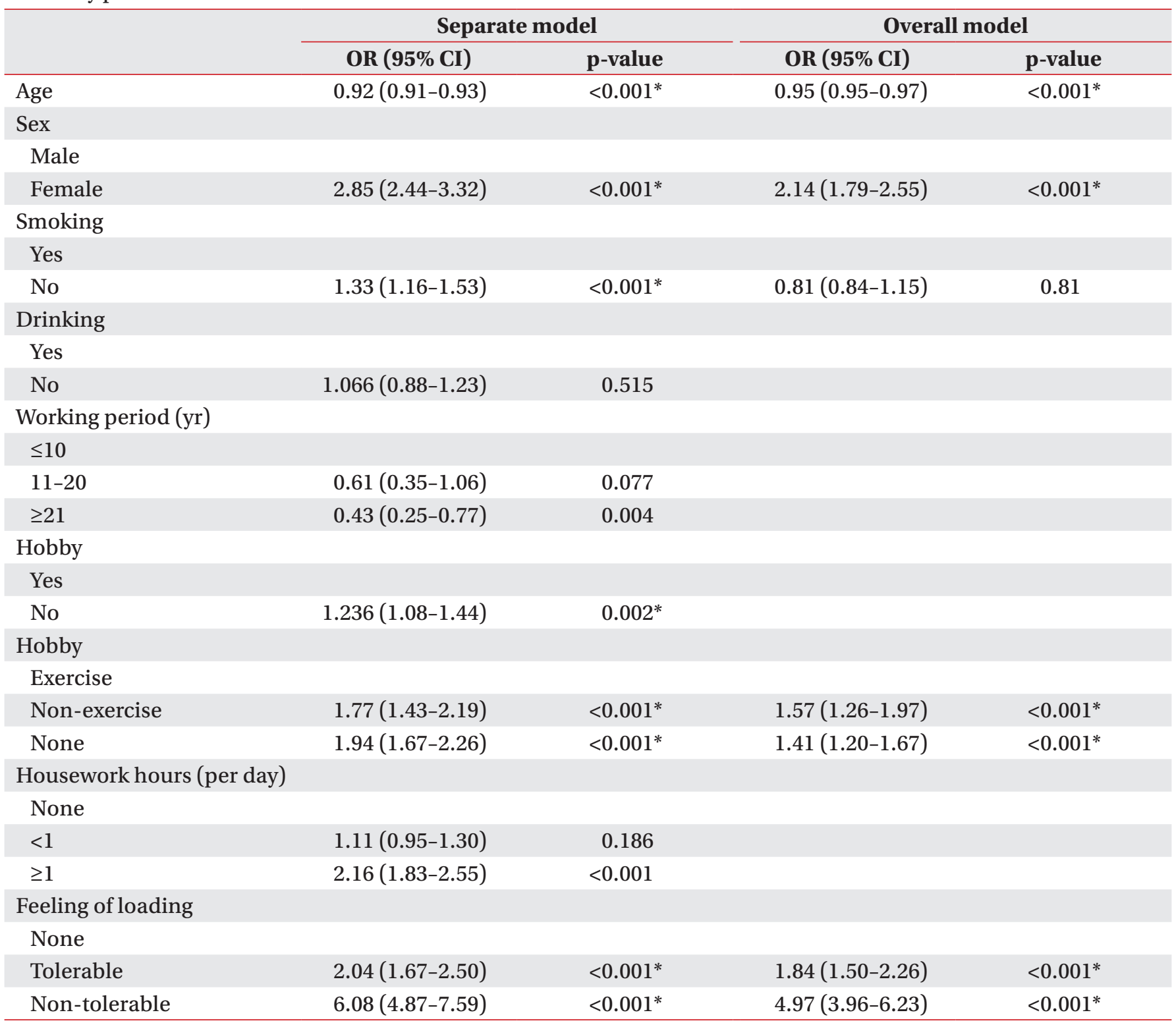

Univariate analysis by simple logistic regression model and multiple logistic regression model after backward stepwise elimination.

${ }^{*} \mathrm{p}<0.05$. 
gender, the number of working years, drinking, smoking, hobby including exercise, housework hours, and feeling of loading, job stress, etc.) on lower extremity pain, logistic regression analysis was performed.

\section{RESULTS}

\section{Cross-tabulation between general characteristics and} measured values in the lower extremity pain group

The mean age of the entire study participants was $43.4 \pm 5.4$ years with the minimum age of 28 years and the maximum age of 59 years. The general characteristics of the lower extremity pain and control groups (age, gender, the number of working years, drinking, smoking, hobbies including exercise, housework hours, and feeling of loading) are presented in Table 1. Those who had a shorter number of working years, no hobbies, longer housework hours, and more feeling of loading tended to have lower extremity pain (Table 1). As a result of cross-tabulation between the presence of lower extremity pain and general characteristics (age, gender, the number of working years, drinking, smoking, hobbies including exercise, housework hours, and feeling of loading), the odds ratio (OR) was 2.85 in females and 1.33 in non-smokers indicating that females and non-smokers experienced more lower extremity pain than males and smokers. The group with no hobbies had a higher incidence of lower extremity pain than the group with hobbies, and there was no statistically significant difference between the non-exercise group and the exercise group (Table 2).

\section{Correlations between job stress and quality of life in each group}

In the result of Pearson correlation analysis between KOSS and each subscale scores of SF-36 in the lower extremity pain group, the correlations between the total job stress score and role-physical and role-emotional were -0.254 , showing negligible correlation, and between the

Table 3. Partial correlation coefficients between occupational stress scale and SF-36 scale in the lower extremity pain and control groups

\begin{tabular}{|c|c|c|c|c|c|c|c|c|c|c|c|}
\hline & & PF & $\mathbf{R P}$ & BP & GH & VT & SF & RE & MH & PCS & MCS \\
\hline \multirow[t]{2}{*}{ JD } & Pain & $-0.054^{*}$ & $-0.149^{*}$ & $-0.124^{*}$ & $-0.090^{*}$ & $-0.132^{*}$ & $-0.162^{*}$ & $-0.130^{*}$ & $-0.150^{*}$ & $-0.080^{*}$ & $-0.151^{*}$ \\
\hline & Control & $-0.088^{*}$ & $-0.160^{*}$ & $-0.168^{*}$ & $-0.150^{*}$ & $-0.206^{*}$ & $-0.162^{*}$ & $-0.162^{*}$ & $-0.204^{*}$ & $-0.141^{*}$ & $-0.217^{*}$ \\
\hline \multirow[t]{2}{*}{ IJC } & Pain & $-0.122^{*}$ & $-0.124^{*}$ & $-0.132 *$ & $-0.181^{*}$ & $-0.247^{*}$ & $-0.160^{*}$ & $-0.077^{*}$ & $-0.201^{*}$ & $-0.183^{*}$ & $-0.253^{*}$ \\
\hline & Control & $-0.108^{*}$ & $-0.087^{*}$ & $-0.110^{*}$ & $-0.171^{*}$ & $-0.227^{*}$ & $-0.092^{*}$ & $-0.045^{*}$ & $-0.159 *$ & $-0.165^{*}$ & $-0.206^{*}$ \\
\hline \multirow[t]{2}{*}{ IC } & Pain & $-0.089 *$ & $-0.139 *$ & $-0.142^{*}$ & $-0.208^{*}$ & $-0.218^{*}$ & $-0.166^{*}$ & $-0.119^{*}$ & $-0.245^{*}$ & $-0.187^{*}$ & $-0.244^{*}$ \\
\hline & Control & $-0.083^{*}$ & $-0.062^{*}$ & $-0.111^{*}$ & $-0.165^{*}$ & $-0.238^{*}$ & $-0.170^{*}$ & $-0.103^{*}$ & $-0.207^{*}$ & $-0.148^{*}$ & $-0.237^{*}$ \\
\hline \multirow[t]{2}{*}{ JI } & Pain & $-0.142^{*}$ & $-0.165^{*}$ & $-0.174^{*}$ & $-0.261^{*}$ & $-0.267^{*}$ & $-0.219 *$ & $-0.170^{*}$ & $-0.289 *$ & $-0.241^{*}$ & $-0.294^{*}$ \\
\hline & Control & $-0.135^{*}$ & $-0.124^{*}$ & $-0.140^{*}$ & $-0.230^{*}$ & $-0.247^{*}$ & $-0.186^{*}$ & $-0.152^{*}$ & $-0.232^{*}$ & $-0.216^{*}$ & $-0.254^{*}$ \\
\hline \multirow[t]{2}{*}{ OS } & Pain & $-0.156^{*}$ & $-0.232^{*}$ & $-0.239 *$ & $-0.295^{*}$ & $-0.315^{*}$ & $-0.264^{*}$ & $-0.232^{*}$ & $-0.336^{*}$ & $-0.269^{*}$ & $-0.345^{*}$ \\
\hline & Control & $-0.183^{*}$ & $-0.173^{*}$ & $-0.214^{*}$ & $-0.228^{*}$ & $-0.353^{*}$ & $-0.254^{*}$ & $-0.323^{*}$ & $-0.242^{*}$ & $-0.207^{*}$ & $-0.359^{*}$ \\
\hline \multirow[t]{2}{*}{ LOR } & Pain & $-0.159^{*}$ & $-0.190^{*}$ & $-0.208^{*}$ & $-0.285^{*}$ & $-0.352^{*}$ & $-0.256^{*}$ & $-0.163^{*}$ & $-0.333^{*}$ & $-0.264^{*}$ & $-0.365^{*}$ \\
\hline & Control & $-0.176^{*}$ & $-0.159^{*}$ & $-0.173^{*}$ & $-0.264^{*}$ & $-0.376^{*}$ & $-0.238^{*}$ & $-0.353^{*}$ & $-0.259 *$ & $-0.191^{*}$ & $-0.386^{*}$ \\
\hline \multirow[t]{2}{*}{ OC } & Pain & $-0.146^{*}$ & $-0.178^{*}$ & $-0.213^{*}$ & $-0.251^{*}$ & $-0.277^{*}$ & $-0.269 *$ & $-0.181^{*}$ & $-0.304^{*}$ & $-0.236^{*}$ & $-0.307^{*}$ \\
\hline & Control & $-0.198^{*}$ & $-0.188^{*}$ & $-0.238^{*}$ & $-0.247^{*}$ & $-0.340^{*}$ & $-0.301^{*}$ & $-0.330^{*}$ & $-0.261^{*}$ & $-0.215^{*}$ & $-0.355^{*}$ \\
\hline \multirow[t]{2}{*}{ OSS } & Pain & $-0.467^{*}$ & $-0.316^{*}$ & $-0.412^{*}$ & $-0.624^{*}$ & $-0.677^{*}$ & $-0.434^{*}$ & $-0.254^{*}$ & $-0.639 *$ & $-0.578^{*}$ & $-0.711^{*}$ \\
\hline & Control & $-0.371^{*}$ & $-0.299^{*}$ & $-0.404^{*}$ & $-0.629^{*}$ & $-0.689^{*}$ & $-0.467^{*}$ & $-0.275^{*}$ & $-0.644^{*}$ & $-0.579^{*}$ & $-0.618^{*}$ \\
\hline
\end{tabular}

SF-36, medical outcome study 36-item short-form health survey; PF, physical functioning; RP, role-physical; BP, bodily pain; GH, general health; VT, vitality; SF, social functioning; RE, role-emotional; MH, mental health; PCS, physical component summary; MCS, mental component summary; JD, job demand; IJC, insufficient job control; IC, interpersonal conflict; JI, job insecurity; OS, organizational system; LOR, lack of reward; OC, occupational climate; OSS, occupational stress.

${ }^{*} \mathrm{p}<0.05$, partial correlation significant. Age, gender, working period, drinking, smoking, hobby, housework hour and feeling of loading were adjusted for partial correlation coefficients between Occupational Stress Scale and SF-36 Scale in control and lower extremity pain group. 


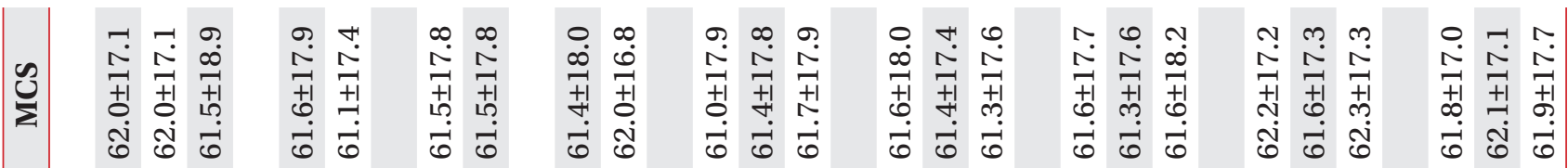

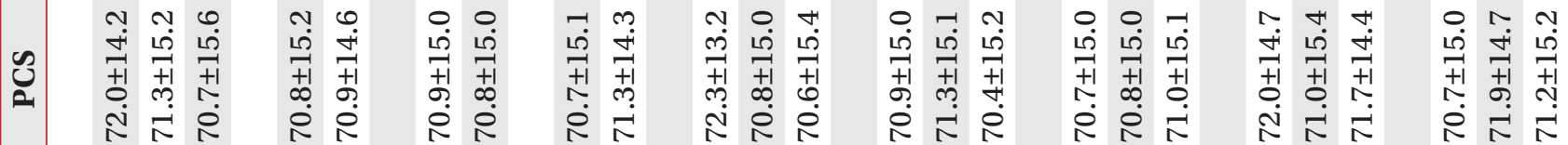

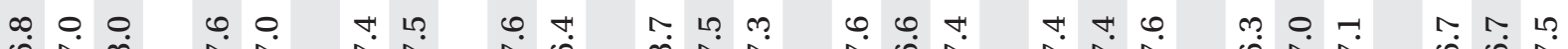

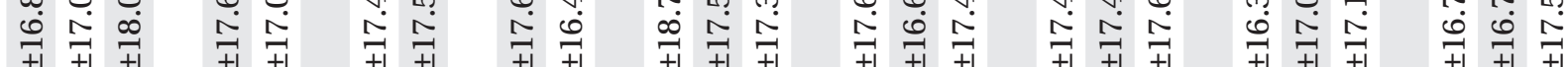
隹

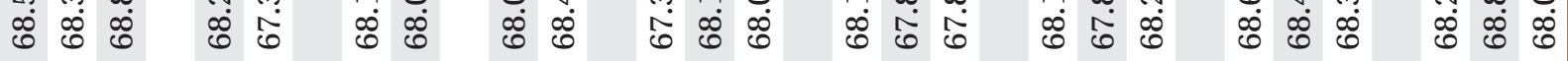
กฺ

ஸे 莳 एं

ติ่ m $+1+$ ๓ं กิ $\pm \stackrel{+1}{\stackrel{+1}{N}}$ ஜ்

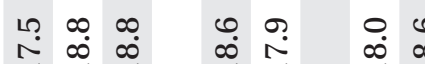

๓

\section{นุ นุ}

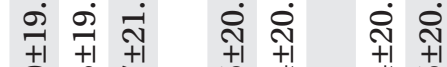

药

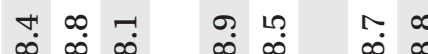

+ุ $+1+1$

官

+1 ț

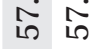

$\infty_{+1}^{\infty}$

$\infty$

路

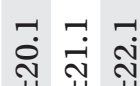

ก +

ก

กุ

곤

ำ

เก กุ

กำ

i

+.

$\begin{array}{ll}\infty & \infty \\ +1 & +1 \\ 0 & +1\end{array}$

வ 8

त. त. 9

นก ก ก เ

m̊

m.

เึ

9)

$\begin{array}{lll}+1 & 7 \\ \infty & +1 \\ 0 & 0 & 0\end{array}$

战

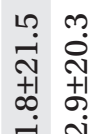

†)

ले

+1 $\begin{array}{lll}+1 & +1 \\ \text { N } & \infty & m\end{array}$

ரீ

H 0 H m $m \infty$

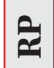

เึ

†

ळ

$\stackrel{+1}{+1}$

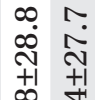

ก)

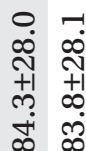

․

() ก $\pi \infty$

๑)

10

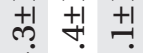

एं

+

வ்

\section{市}

ल $\begin{array}{ll}0 & 10 \\ +1 & +1 \\ N & \infty\end{array}$

ஜ் $\stackrel{\infty}{-\infty}$

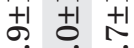

$\infty$ i

$\infty \infty_{+1}^{\infty} \infty$

$\begin{array}{lll}+1 & +1 & +1 \\ 0 & \text { m. } & 0 \\ 0 & 0 & 0\end{array}$

เึ่

+1 $\begin{array}{ll}7 & +1 \\ -1 & \infty\end{array}$

合 in

ஹั

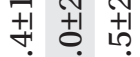

ํํำ

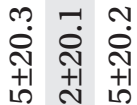

मी

가

๑

ก. 0

จิ

+1 +1 ન

ก.

$\infty \stackrel{\infty}{-\infty}$

苟

路 命

๓

กิ

i $\stackrel{\text { i }}{\mathrm{i}}$

N

ஸั่

t1 +1 t1

เึ่ เึ่

ஸे

ก

ळ

H. 0.0

$\stackrel{9}{9}$

+1 + +1

药 in

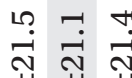

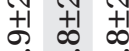

i

ণั่ กั กิ

$+\infty+1$

๗்
กุ

ஸे $\underset{+1}{\stackrel{4}{+1}} \stackrel{\dot{7}}{+1}$

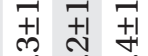
ले
+1 $+\begin{array}{ll}+1 \\ +1\end{array}$

กิ
궁

क m

$+1+1$

ळे

$\infty \sim N \quad$ N 0 N $\dot{\sigma} \dot{\sigma} \dot{\sigma} \dot{\sigma}$

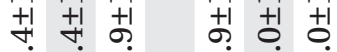

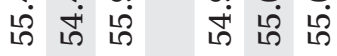
†े

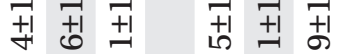
官 m

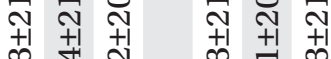
i $\stackrel{N}{N}$ i $r-\pi \quad 0.0 .10$ ஸ่

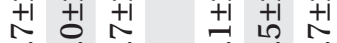
ஜ

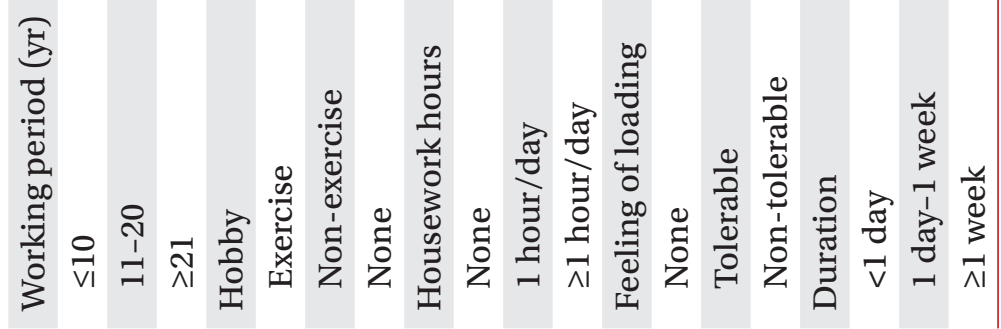




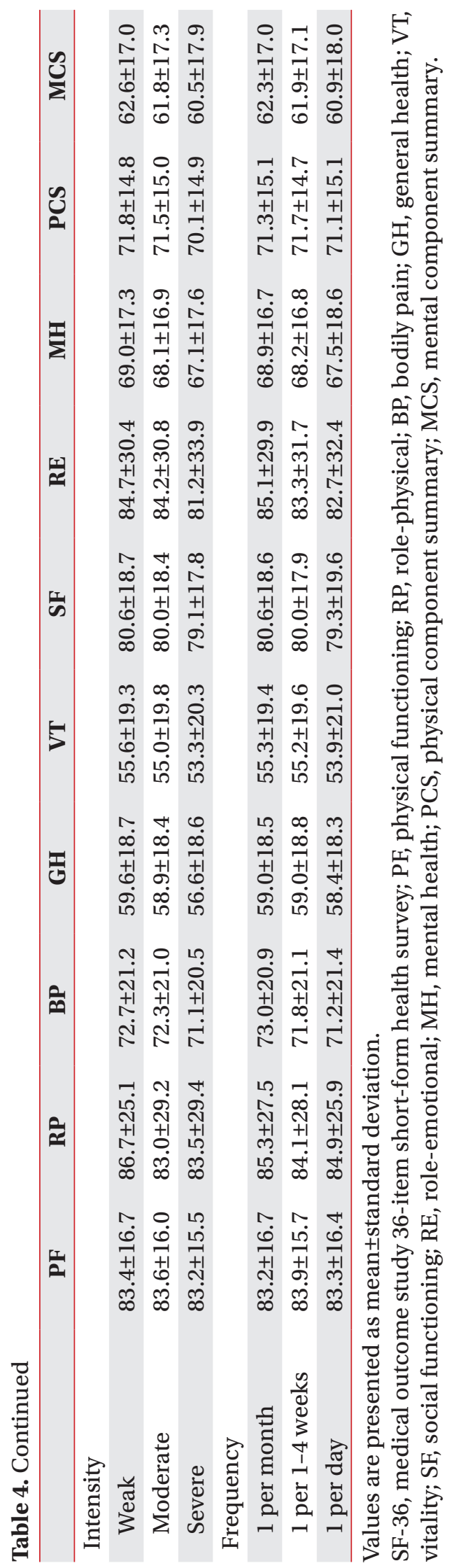

total job stress score and role-physical were - 0.316 , showing low negative correlations. The correlations between the total job stress score and physical functioning, bodily pain, general health, vitality, social functioning, mental health and physical component summary (PCS) were $-0.467,-0.412,-0.624,-0.677,-0.434,-0.639,-0.578$, respectively, showing moderate negative correlations. The correlation between the total job stress score and mental component summary (MCS) were -0.711 , showing high negative correlation.

In the result of Pearson correlation analysis between KOSS and each subscale scores of SF-36 in the control group, the correlations between the total job stress score and role-physical, and role-emotional were -0.299 , and -0.275 , showing negligible correlations. The correlations between the total job stress score and physical functioning, bodily pain, general health, vitality, social functioning, mental health, PCS, and MCS were $0.371,-0.404$, $-0.629,-0.689,-0.467,-0.644,-0.579$, and -0.618 , respectively, showing moderate negative correlations (Table 3 ).

\section{Differences in job stress and QOL between the two groups}

In the result of comparison in KOSS and SF-36 scores between the lower extremity pain and control groups, there were no significant differences in all items between the two groups. In the result of comparison of SF-36 scores after dividing the lower extremity pain group into small groups according to age, gender, the number of working years, drinking, smoking, hobbies including exercise, housework hours, feeling of loading, and the duration, intensity, and frequency of lower extremity pain, there were no significant differences in all items between the small groups (Table 4). Additionally, as a result of comparing KOSS, there were no significant differences in all items between the small groups (Table 5).

\section{Logistic regression analysis}

Logistic regression analysis result for each variable in the entire subjects showed that younger age, female gender, no smoking history, non-exercise hobbies or no hobbies, and feeling of loading were analyzed as significant variables causing lower extremity pain. As a result of multiple regression including the aforementioned significant variables, younger age, female gender, non-exercise hobbies or no hobbies, and feeling of loading were found 
Table 5. Comparison of occupational stress scale according to variables in the lower extremity pain group

\begin{tabular}{|c|c|c|c|c|c|c|c|c|}
\hline & JD & IJC & IC & JI & OS & LOR & OC & OSS \\
\hline \multicolumn{9}{|l|}{ Age (yr) } \\
\hline$\leq 39$ & $50.0 \pm 11.6$ & $50.0 \pm 13.5$ & $60.7 \pm 13.9$ & $53.3 \pm 18.7$ & $49.0 \pm 13.5$ & $53.4 \pm 15.2$ & $37.2 \pm 13.5$ & $59.8 \pm 3.8$ \\
\hline $40-49$ & $50.3 \pm 11.6$ & $49.7 \pm 14.3$ & $60.3 \pm 14.7$ & $53.6 \pm 19.8$ & $48.8 \pm 14.4$ & $52.4 \pm 15.8$ & $37.2 \pm 13.7$ & $59.7 \pm 4.2$ \\
\hline$\geq 50$ & $51.1 \pm 12.7$ & $51.6 \pm 12.9$ & $59.5 \pm 13.3$ & $52.9 \pm 19.0$ & $48.4 \pm 14.1$ & $53.2 \pm 15.2$ & $38.6 \pm 13.7$ & $60.1 \pm 3.3$ \\
\hline \multicolumn{9}{|l|}{ Sex } \\
\hline Male & $50.2 \pm 11.6$ & $50.3 \pm 14.1$ & $60.3 \pm 14.2$ & $53.4 \pm 19.3$ & $48.9 \pm 13.9$ & $52.8 \pm 15.5$ & $37.3 \pm 13.2$ & $59.8 \pm 4.0$ \\
\hline Female & $50.4 \pm 11.8$ & $49.1 \pm 13.7$ & $60.5 \pm 14.6$ & $53.7 \pm 19.7$ & $48.7 \pm 14.5$ & $52.6 \pm 15.6$ & $37.3 \pm 14.5$ & $59.7 \pm 4.0$ \\
\hline \multicolumn{9}{|l|}{ Smoking } \\
\hline Yes & $49.6 \pm 11.9$ & $50.3 \pm 14.2$ & $60.4 \pm 14.9$ & $53.3 \pm 19.2$ & $49.1 \pm 13.8$ & $53.0 \pm 15.7$ & $37.3 \pm 13.6$ & $59.7 \pm 4.4$ \\
\hline No & $50.5 \pm 11.5$ & $49.7 \pm 13.9$ & $60.4 \pm 14.2$ & $53.5 \pm 19.5$ & $48.7 \pm 14.3$ & $52.7 \pm 15.5$ & $37.4 \pm 13.7$ & $59.7 \pm 3.9$ \\
\hline \multicolumn{9}{|l|}{ Drinking } \\
\hline Yes & $50.3 \pm 11.7$ & $50.1 \pm 14.0$ & $60.4 \pm 14.2$ & $53.6 \pm 19.5$ & $48.8 \pm 14.3$ & $52.3 \pm 15.8$ & $37.3 \pm 13.7$ & $59.8 \pm 4.0$ \\
\hline No & $50.4 \pm 11.5$ & $49.2 \pm 14.2$ & $60.0 \pm 15.4$ & $53.0 \pm 19.0$ & $49.0 \pm 13.2$ & $52.1 \pm 13.9$ & $37.3 \pm 13.3$ & $59.4 \pm 4.2$ \\
\hline \multicolumn{9}{|c|}{ Working period (yr) } \\
\hline$\leq 10$ & $51.0 \pm 13.8$ & $51.1 \pm 11.0$ & $61.2 \pm 17.3$ & $54.9 \pm 21.3$ & $49.8 \pm 12.0$ & $55.5 \pm 13.5$ & $35.9 \pm 16.2$ & $60.1 \pm 3.7$ \\
\hline $11-20$ & $50.1 \pm 11.4$ & $50.0 \pm 14.1$ & $60.1 \pm 14.4$ & $53.8 \pm 19.2$ & $48.6 \pm 14.2$ & $52.4 \pm 15.6$ & $37.3 \pm 13.5$ & $59.6 \pm 4.1$ \\
\hline$\geq 21$ & $51.3 \pm 12.6$ & $50.1 \pm 13.4$ & $61.7 \pm 13.6$ & $51.5 \pm 20.4$ & $50.4 \pm 13.7$ & $54.1 \pm 15.5$ & $37.8 \pm 14.0$ & $60.3 \pm 3.7$ \\
\hline \multicolumn{9}{|l|}{ Hobby } \\
\hline Exercise & $50.5 \pm 11.5$ & $50.0 \pm 14.0$ & $60.3 \pm 14.2$ & $54.0 \pm 19.2$ & $48.9 \pm 14.2$ & $52.4 \pm 15.5$ & $37.3 \pm 13.4$ & $59.8 \pm 4.1$ \\
\hline Non-exercise & $51.2 \pm 11.1$ & $50.2 \pm 13.5$ & $61.0 \pm 14.6$ & $55.4 \pm 19.6$ & $48.0 \pm 14.1$ & $53.1 \pm 16.4$ & $38.5 \pm 13.7$ & $60.1 \pm 4.0$ \\
\hline None & $50.3 \pm 12.2$ & $50.0 \pm 14.2$ & $60.4 \pm 14.6$ & $52.7 \pm 19.8$ & $49.1 \pm 14.1$ & $53.3 \pm 15.4$ & $36.9 \pm 14.1$ & $59.5 \pm 4.0$ \\
\hline \multicolumn{9}{|l|}{ Housework hours } \\
\hline None & $50.0 \pm 12.0$ & $50.1 \pm 13.6$ & $60.4 \pm 14.0$ & $53.6 \pm 18.4$ & $48.6 \pm 14.3$ & $52.8 \pm 15.7$ & $37.4 \pm 12.6$ & $59.7 \pm 4.0$ \\
\hline 1 hour/day & $50.8 \pm 11.8$ & $50.6 \pm 14.3$ & $60.5 \pm 14.5$ & $52.8 \pm 19.4$ & $49.4 \pm 13.9$ & $53.0 \pm 15.8$ & $37.3 \pm 13.8$ & $59.9 \pm 4.2$ \\
\hline$\geq 1$ hour/day & $50.0 \pm 11.3$ & $49.1 \pm 13.9$ & $60.3 \pm 14.5$ & $54.0 \pm 20.1$ & $48.4 \pm 14.2$ & $52.4 \pm 15.2$ & $37.2 \pm 14.1$ & $59.5 \pm 4.0$ \\
\hline \multicolumn{9}{|l|}{ Feeling of loading } \\
\hline None & $52.4 \pm 12.3$ & $51.6 \pm 14.1$ & $60.1 \pm 12.3$ & $53.1 \pm 20.1$ & $47.8 \pm 14.3$ & $53.3 \pm 15.6$ & $38.4 \pm 13.6$ & $60.3 \pm 3.7$ \\
\hline Tolerable & $50.2 \pm 11.9$ & $50.0 \pm 13.9$ & $60.7 \pm 14.1$ & $53.6 \pm 19.0$ & $48.9 \pm 14.3$ & $52.7 \pm 15.6$ & $37.1 \pm 13.7$ & $59.8 \pm 4.0$ \\
\hline Non-tolerable & $50.0 \pm 11.2$ & $49.3 \pm 14.1$ & $60.0 \pm 15.1$ & $53.4 \pm 19.8$ & $48.9 \pm 13.9$ & $53.0 \pm 15.5$ & $37.2 \pm 13.6$ & $59.6 \pm 4.1$ \\
\hline \multicolumn{9}{|l|}{ Duration } \\
\hline$<$ l day & $50.1 \pm 10.9$ & $51.7 \pm 12.2$ & $60.5 \pm 13.2$ & $54.2 \pm 18.8$ & $49.1 \pm 13.7$ & $52.1 \pm 15.0$ & $37.4 \pm 14.2$ & $60.0 \pm 3.5$ \\
\hline 1 day-1 week & $49.8 \pm 11.9$ & $49.6 \pm 13.8$ & $60.3 \pm 14.4$ & $52.9 \pm 19.4$ & $49.1 \pm 14.2$ & $53.0 \pm 15.7$ & $36.9 \pm 13.4$ & $59.6 \pm 4.1$ \\
\hline$\geq 1$ week & $50.8 \pm 11.7$ & $49.5 \pm 14.7$ & $60.4 \pm 14.7$ & $53.9 \pm 19.7$ & $48.5 \pm 14.2$ & $52.7 \pm 15.7$ & $37.8 \pm 13.7$ & $59.8 \pm 4.2$ \\
\hline \multicolumn{9}{|l|}{ Intensity } \\
\hline Weak & $50.0 \pm 11.9$ & $50.5 \pm 14.2$ & $60.7 \pm 14.4$ & $52.3 \pm 19.0$ & $49.5 \pm 14.5$ & $53.4 \pm 16.0$ & $37.3 \pm 13.7$ & $59.9 \pm 4.1$ \\
\hline Moderate & $50.4 \pm 11.2$ & $49.5 \pm 13.2$ & $60.4 \pm 13.9$ & $53.9 \pm 19.1$ & $49.2 \pm 13.7$ & $52.9 \pm 14.9$ & $36.8 \pm 13.8$ & $59.7 \pm 3.8$ \\
\hline Severe & $50.5 \pm 11.9$ & $49.6 \pm 14.7$ & $60.1 \pm 15.0$ & $54.3 \pm 20.2$ & $47.6 \pm 14.2$ & $51.9 \pm 15.9$ & $38.0 \pm 13.4$ & $59.6 \pm 4.2$ \\
\hline \multicolumn{9}{|l|}{ Frequency } \\
\hline 1 per month & $50.5 \pm 12.0$ & $50.5 \pm 13.3$ & $60.8 \pm 14.2$ & $53.5 \pm 19.0$ & $49.4 \pm 13.9$ & $53.1 \pm 15.3$ & $37.3 \pm 13.3$ & $59.9 \pm 4.0$ \\
\hline 1 per $1-4$ weeks & $50.2 \pm 11.2$ & $49.4 \pm 14.5$ & $59.6 \pm 14.9$ & $53.1 \pm 19.0$ & $48.3 \pm 14.6$ & $52.7 \pm 16.0$ & $37.3 \pm 14.2$ & $59.5 \pm 4.2$ \\
\hline 1 per day & $49.9 \pm 11.9$ & $49.3 \pm 14.5$ & $61.3 \pm 12.9$ & $54.7 \pm 19.8$ & $48.5 \pm 13.1$ & $52.7 \pm 15.6$ & $37.7 \pm 13.1$ & $59.7 \pm 4.0$ \\
\hline
\end{tabular}

Values are presented as mean \pm standard deviation.

JD, job demand; IJC, insufficient job control; IC, interpersonal conflict; JI, job insecurity; OS, organizational system; LOR, lack of reward; OC, occupational climate; OSS, occupational stress. 
as the variables independently associated with lower extremity pain (Table 2).

\section{Linear regression analysis to predict $\mathrm{OOL}$}

In linear regression analysis to predict the quality of life score from the total job stress score, the simple regression equations were ' $\mathrm{PCS}=57.531+(-0.031) \times$ total job stress score' and 'MCS=57.332+(-0.039) $\times$ total job stress score', and $R^{2}$ values were 0.013 and 0.029 , respectively.

\section{DISCUSSION}

According to the occupational health standards established by the Korea Ministry of Employment and Labor, 'musculoskeletal disorders' refer to the disorders caused by the factors such as repetitive movements, inappropriate working postures, use of excessive force, physical contact with sharp surfaces, vibration, and temperature, which occur in the neck, shoulder, waist, nerves of upper and lower extremities, muscles and surrounding tissues. Additionally, according to the notification of the Korea Ministry of Employment and Labor, 'musculoskeletal burden tasks' refer to the work of repeating the same movements using neck, shoulder, elbow, wrist or lower extremities for more than 2 hours a day and the work of requiring the postures of sitting on knees or lifting heavy objects for more than 2 hours.

Due to the development of personal office machines, most office workers working with a computer, and as the dependency on it increases, computer use time tends to increase gradually. As a result, work-related musculoskeletal disorders have emerged as an important social problem. As major risk factors for work-related musculoskeletal disorders that develop in computer-based office workers, ergonomic stresses were mainly suggested including working posture, degree of repetitive work, work time, and design of work space [8-10]. On the other hand, there have been arguments about the importance of psychosocial factors, such as work satisfaction, workload fluctuation, and mental stress, or individual factors, such as personality and mood of employees $[11,12]$. In addition, WRMSDs are known to be caused by interactions among ergonomic stresses, psychosocial factors, and individual factors with the influences of cultural/social factors [13].

In this study, the factors that showed a statistically sig- nificant relationship with lower extremity pain included age, gender, hobby, and feeling of loading. With regard to previous studies on the association between the age and lower extremity pain, there is a study showing that the age increases the risk [14], while there are studies arguing that there is no association between the age and the risk. However, in general, degenerative changes of the musculoskeletal system due to aging are inevitable. The prevalence of vascular diseases and neurological diseases increases, and repetitive office work accelerates such changes. As a result, lower extremity pain occurs frequently [15]. However, in this study, as the age was younger, lower extremity pain increased, as shown in a previous study for office workers [16]. As the number of working years increases, workers who have adapted to the job continue to work, and more workers who are unable to adjust to the job physically and mentally leave by retiring from the company or moving to another company. Long-term employees tend to move to a position requiring less difficult tasks, and such phenomenon causes the healthy worker effect, which seems to have affected the above result.

Also, this study has a limitation in that additional analysis on the decrease of age and the increase of lower extremity pain could not be performed because the questionnaire only includes the number of working years without the information on the workload and work intensity.

The finding of a higher risk in females than in males is consistent with the results of previous studies [17-19] that reported a higher prevalence of lower extremity pain in females. The reason for this phenomenon seems to be that the burden and intensity of housework are higher in female workers than in male workers. As a result, lower extremity pain occurs more frequently in females. However, the opposite result has been reported [20]. Thus, further studies need to be done in the future after removing the confounding factors such as labor burden excluding work hours. In this study, the ORs of those with nonexercise hobbies and those without hobbies were 1.57 and 1.41, respectively, compared to those with exercise hobbies. There is no consensus about the association between general exercise and lower extremity pain. However, there are previous study [21] showing that exercise was effective on preventing lower extremity pain like the result of this study. This study suggests that regular exercise is necessary to prevent lower extremity pain in 
clerical VDT workers who do not carry out physical labor, although there is a limitation in that the type, frequency, and hours of specific exercise performed by the subjects were not investigated.

This study is meaningful in that it was a large-scale study targeting VDT workers who work in a static working environment, compared to previous studies conducted mainly on workers who performed dynamic work. It can be assumed that the static posture of VDT workers may cause chronic venous insufficiency, and the work stress may increase the tension of the muscles, thereby causing lower extremity pain. The OR of the group that felt heavy feeling of loading was 4.97 , which was much higher than the group without feeling of loading. This suggests that the dynamic and static work environments, such as VDT work, may cause feeling of loading, thus lower extremity pain may occur frequently due to such factors. Smoking is a causative factor of peripheral arterial disease, such as Burger's disease, and affects cartilage loss of the knee joint [22]. In this study, lower extremity pain in smokers and non-smokers was analyzed by simple logistic regression analysis. The OR of the non-smokers was 1.33, reflecting the high proportion of women with a higher prevalence of lower extremity pain in the non-smoker group, thus the statistical significance disappeared in the multivariate logistic regression analysis. In many studies conducted in Korea, job stress has been measured mainly with the Job Content Questionnaire [23] and translated into Korean, which means that foreign tools have been used without consideration of organizational and cultural characteristics of Korea. Therefore, in this study, the KOSS, which was developed by the Institute of Occupational Safety and Health in 2005 and completed the standardization process, was used [2]. The KOSS measures eight items including job demand, insufficient job control, interpersonal conflict, job insecurity, organization system, lack of reward, and occupational climate, and total score. It has the advantage of being able to identify not only job demand and job autonomy that have been emphasized in previous job stress studies but also other various stress factors in the workplace [2]. The mean total score of job stress of VDT workers was 59.7 points in the lower extremity pain group and 58.8 points in the control group, which fell under the upper 25th percentile based on the reference values published by the developers of KOSS. In terms of detailed items, the pain and control groups both fell under the upper 25th percentile in the interpersonal conflict and belong to the upper 50th percentile in all other items, meaning that the subjects' job stress was high overall. Since the two groups both were in the stressed group, and the standard deviation of the total score was relatively small, it was difficult to make a real comparison for the occurrence of lower extremity pain depending on the degree of job stress.

In this study, the associations of lower extremity pain with quality of life and job stress were investigated in VDT workers with the typical quality of life measurement scale, SF-36, that has been widely used worldwide since its development in 1992. There were no differences in all items of SF-36 between the pain and control groups, and no significant results were shown in the sub-groups divided according to each variable within the pain group. This result is not consistent with the result of a previous study [24] that the SF-36 score was significantly lower in people with musculoskeletal disorders than in healthy individuals. The reason seems to be that the previous study compared the patient group who met the exact diagnosis criteria with the control group consisting of normal people without pain, while this study compared the workers with subjective symptoms with the workers without subjective symptoms. However, despite the above result of the QOL in the lower extremity pain group, regression analysis showed that the total job stress score has an explanation power of $1.3 \%$ for the physical factor of the quality of life and an explanation power of $2.9 \%$ for the mental factor. This result implies that the job stress of VDT workers affects the QOL of individuals regardless of the presence of lower extremity pain, which seems to be clinically meaningful. Previous studies have focused on the neck and upper extremity pain of VDT workers with a relatively high prevalence, thus studies on lower extremity pain are very rare. Messing et al. [19] mentioned female gender, old age, lack of exercise, and prolonged standing at work as independent causes of lower extremity pain in VDT workers. This result is very similar to our result and is meaningful because it suggests that the worker's working posture is associated with lower extremity pain. In order to prevent work-related lower extremity pain, the KOSHA recommends reducing the time of standing work, maintaining the lordosis of the spine by attaching the lumbar support to the chair during long-term sedentary work, using a footrest, and giving 
space to the knees and feet. A study on the working posture and lower extremity pain is currently underway, and further studies are required because the working posture is inferred to be associated with lower extremity pain.

There are several limitations of this study. First, since symptoms and many variables were measured with a questionnaire in this study, there is a possibility that the subjective tendency of the respondent was involved, and the difference in complaining of the lower extremity pain was not standardized. However, due to the nature of musculoskeletal disorders, it is not easy to completely exclude the subjectivity of the patient, thus it is thought that detailed studies should be carried out in the future using various methods such as observation and interview to supplement this part. Second, the ergonomic factors related to the occurrence of lower extremity pain were not examined such as the angles of the lower extremity and body of the workers, and the heights of the worktable, shape of the chair, computer monitor, keyboard, and the mouse position. Therefore, in-depth analysis of the risk factors for lower extremity pain could not be sufficiently done. As reviewed in the above consideration, since the posture and working environment of the worker are closely related to lower extremity pain, further studies considering on these points need to be conducted.

In this study, a comprehensive analysis was performed on the work-related lower extremity pain, general characteristics, job stress, and QOL of office workers who used computers a lot. In VDT workers, the job stress score was higher than the average, and as the stress increased, the QOL decreased. In addition, it was found that younger age, female gender, non-exercise hobbies, and serious feeling of loading affected the lower extremity pain of VDT workers. In order to clarify the risk factors related to VDT workers with lower extremity pain, supplementary studies with long-term follow-up are required considering the ergonomic factors, such as worker's working posture.

\section{CONFLICT OF INTEREST}

No potential conflict of interest relevant to this article was reported.

\section{REFERENCES}

1. Mohr SN, Shalat SL. Clinical occupational and environmental medicine. 2nd ed. Philadelphia: Saunders; 2005. p. 227-32.

2. Chang SJ, Koh SB, Kang D, Kim SA, Kang MG, Lee CG, et al. Developing an occupational stress scale for Korean employees. Korean J Occup Environ Med 2005; 17:297-317.

3. Oh KT, Kwak EJ, Ju EK, Kim TH, Lee JH, Chung WT, et al. Health-related quality of life in Korean patients with rheumatic diseases. J Korean Rheum Assoc 2002; 9(Suppl):S39-59.

4. Rah UW, Kim KM, Lee IY, Shim DS, Rhie KS, Im ID, et al. Quality of life and life satisfaction of the registered disabled persons in Uiwang city. J Korean Acad Rehabil Med 2002;26:615-25.

5. Ware JE Jr, Sherbourne CD. The MOS 36-item shortform health survey (SF-36). I. Conceptual framework and item selection. Med Care 1992;30:473-83.

6. Son S, Pyun SB, Kim SD. Assessment of quality of life in lower limb amputees using short-form 36. J Korean Acad Rehabil Med 2001;25:505-13.

7. Mukaka MM. Statistics corner: a guide to appropriate use of correlation coefficient in medical research. Malawi Med J 2012;24:69-71.

8. Larsson B, Sogaard K, Rosendal L. Work related neckshoulder pain: a review on magnitude, risk factors, biochemical characteristics, clinical picture and preventive interventions. Best Pract Res Clin Rheumatol 2007;21:447-63.

9. Ortiz-Hernandez L, Tamez-Gonzalez S, Martinez-Alcantara S, Mendez-Ramirez I. Computer use increases the risk of musculoskeletal disorders among newspaper office workers. Arch Med Res 2003;34:331-42.

10. Subratty AH, Korumtollee F. Occupational overuse syndrome among keyboard users in Mauritius. Int J Occup Environ Med 2005;9:71-5.

11. Bernard B, Sauter S, Fine L, Petersen M, Hales T. Job task and psychosocial risk factors for work-related musculoskeletal disorders among newspaper employees. Scand J Work Environ Health 1994;20:417-26.

12. Bongers PM, Ijmker S, van den Heuvel S, Blatter BM. Epidemiology of work related neck and upper limb problems: psychosocial and personal risk factors (part I) and effective interventions from a bio behavioural 
perspective (part II). J Occup Rehabil 2006;16:279302.

13. Devereux JJ, Vlachonikolis IG, Buckle PW. Epidemiological study to investigate potential interaction between physical and psychosocial factors at work that may increase the risk of symptoms of musculoskeletal disorder of the neck and upper limb. Occup Environ Med 2002;59:269-77.

14. Wijnhoven HA, de Vet HC, Picavet HS. Explaining sex differences in chronic musculoskeletal pain in a general population. Pain 2006;124:158-66.

15. Lacroix P, Aboyans V, Preux PM, Houles MB, Laskar M. Epidemiology of venous insufficiency in an occupational population. Int Angiol 2003;22:172-6.

16. Lee EC, Kim HC, Jung DY, Kim DH, Leem JH, Park SG. Association between job-stress and VDT work, and musculoskeletal symptoms of neck and shoulder among white-collar workers. Korean J Occup Environ Med 2007;19:187-95.

17. de Zwart BC, Broersen JP, Frings-Dresen MH, van Dijk FJ. Musculoskeletal complaints in The Netherlands in relation to age, gender and physically demanding work. Int Arch Occup Environ Health 1997;70:352-60.

18. Hooftman WE, van der Beek AJ, Bongers PM, van
Mechelen W. Gender differences in self-reported physical and psychosocial exposures in jobs with both female and male workers. J Occup Environ Med 2005; 47:244-52.

19. Messing K, Tissot F, Stock S. Distal lower-extremity pain and work postures in the Quebec population. Am J Public Health 2008;98:705-13.

20. Croft PR, Rigby AS. Socioeconomic influences on back problems in the community in Britain. J Epidemiol Community Health 1994;48:166-70.

21. Yi CH, Park JR, Cha AR, Koh KW, Kim YW, Lee SI. A study on the risk factors of low back pain in computer terminal operators. Korean J Occup Environ Med 1999;11:264-75.

22. Amin S, Niu J, Guermazi A, Grigoryan M, Hunter DJ, Clancy $\mathrm{M}$, et al. Cigarette smoking and the risk for cartilage loss and knee pain in men with knee osteoarthritis. Ann Rheum Dis 2007;66:18-22.

23. Karasek JR, Robert A. Job demands, job decision latitude, and mental strain: implications for job redesign. Adm Sci Q 1979;24:285-308.

24. Kim CG, Oh KT, Choe JY, Bae SC. Health-Related quality of life in Korean patients with rheumatoid arthritis. J Korean Rheum Assoc 2002;9(Suppl):S60-72. 